\title{
A PARAMETRIC STUDY ON BUCKLING OF R/C COLUMNS EXPOSED TO FIRE
}

\author{
Lijie Wang, Robby Caspeele \& Luc Taerwe \\ Ghent University, Department of Structural Engineering, Magnel Laboratory for Concrete Research, Ghent, Belgium
}

\begin{abstract}
Buckling of concrete columns is a major issue in fire design, since heating of the columns will result in loss of stiffness and strength in the outer concrete layers. In the Dutch concrete code NEN 6720 (NEN, 1995), a quasi-linear theory of elasticity (KLE) method is provided for columns at ambient temperature. However, no literature is available showing whether this method could be adopted for elevated temperatures. Hence, an efficient calculation tool is needed to validate the applicability of this method in case of fire. As a first step, a cross-sectional calculation tool is introduced to calculate interaction curves of columns at ambient temperature. Further, the interaction diagrams obtained with this numerical method as well as the stiffness method provided in (Eurocode, 2004) and the KLE method are compared. Then, an assumed formula in the KLEmethod for the nominal stiffness calculation is discussed considering interaction curves of columns in case of an ISO 834 fire. Finally, parameters like the fire duration and the slenderness ratio are investigated.
\end{abstract}

Keywords: Buckling, interaction curves, KLE- method, fire resistance, the slenderness ratio

\section{INTRODUCTION}

The buckling of eccentrically-loaded columns because of second-order bending moments is very rare in reinforced-concrete structures, but situations characterized by the risk of buckling are becoming more frequent due to the increasing use of high-performance concretes leading to reduced sectional dimensions and more slender columns. This risk is even greater in fire, as concrete damage lead to sectional reductions. Column buckling in R/C, therefore, should be thoroughly investigated. The aim of a column buckling analysis is to determine the maximum load that a column can support. However, the buckling load is not simply decided by the strength of materials. Instead, it is governed by the stiffness and geometry of the column. Hence, the nominal stiffness of columns is usually adopted to calculate the buckling load.

In EN 1992-1-1 (Eurocode, 2004), a simplified method - the stiffness method is introduced. This method presents a calculation model based on an estimated nominal stiffness, which is further adopted to predict the design moment of the cross-section with respect to the bending moment and the axial force. At the same time, a quasi-linear theory of elasticity (KLE) method is illustrated in the Dutch concrete code NEN 6720 (NEN, 1995). The KLE-method makes it possible to determine the physical nonlinear behavior for a concrete structure while using the linear theory of elasticity. The nominal stiffness method and the KLE-method are both based on the estimation of the stiffness and are proven to be feasible for determining the second-order effects of braced columns at ambient temperature. With respect to fire, a reduced cross-section as well as a relevant stiffness is proposed in EN 1992-1-2 (Eurocode 2, 2004). However, the KLE-method has not been verified at elevated temperatures. Therefore, the applicability of the KLE-method in case of fire still needs to be discussed.

As a first step in this paper, a cross-sectional numerical calculation tool is introduced to calculate interaction curves taking into account second-order effects. Then, a typical column at ambient temperature is analyzed adopting the numerical method, the nominal stiffness method as well as the KLE-method. Further, the same column in case of four-sided exposure to an ISO 834 standard fire 
is studied with the KLE-method and the numerical method. Comparing interaction curves based on these two methods, the assumed point for the nominal stiffness calculation is discussed. Finally, the influence of the fire duration of the slenderness ratio is investigated.

\section{CALCULATION MODEL AND METHOD}

\subsection{Numerical Method}

A cross-sectional numerical calculation tool is proposed to calculate the combined effect of an axial force $(\mathrm{N})$ and bending moment $(\mathrm{M})$ on columns, taking into account material strength reduction and thermal strains in case of fire. This calculation model takes the material model (siliceous aggregate concrete and steel) of EN 1992-1-2 (Eurocode 2, 2004) as a basis for both the thermal analysis and structural analysis. Assumptions are made for a simplified calculation: 1) concrete has no tensile strength; 2) plane sections remain plane 3) the temperature of the steel is assumed to be uniform over the steel cross-section.

This numerical method is based on a cross-sectional calculation for both the thermal analysis and the structural analysis. As the first step for the node temperature calculation, the cross-section under consideration is discretized into small rectangles. The heat transfer and temperature calculation is based on Fourier's law for conduction, Newton's law for convection and Stefan-Boltzmann's law for radiation. Consequently, the heat flow between nodes of a cross-section can be calculated by defining a matrix. Then, the thermal strains $\varepsilon_{\text {th }}$ are calculated using the formulas provided in EN 1992-1-2 (Eurocode 2, 2004) according to the temperatures in the nodes. Finally, the mechanical strain $\varepsilon_{\text {mech }}\left(\varepsilon_{\text {mech }}=\varepsilon_{\text {tot }}-\varepsilon_{\text {th }}\right)$ as well as interaction curves of columns are obtained (see Wang et al., 2015).

\subsection{KLE-Method Described in NEN 6720 (NEN 1995)}

The KLE-method is based on the quasi-linear theory of elasticity. In clause 7.2.3 of the NEN 6720 (NEN, 1995), it is stated that the stiffness of the concrete column equals the stiffness of the same structure subjected to a load of $0.8 \mathrm{M}_{\mathrm{Ed}}$ (shown in Fig. 1). This reduction of the bending moment is based on the assumption that $0.8 \mathrm{M}_{\mathrm{Ed}}$ is an average between the bending moment in the ultimate limit state (ULS) and the serviceability limit state (SLS).

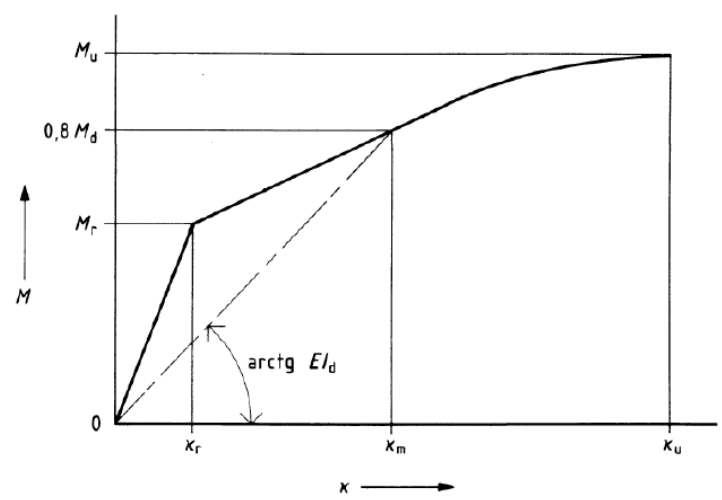

Fig. 1 Quasi linear stiffness according to figure 21 of NEN 6720

Once the stiffness is estimated, the buckling load can be calculated as the expression shown in Eq. (1).

$$
N_{B}=\frac{\pi^{2} E I}{l_{0}^{2}}
$$

where EI a representative bending stiffness

$\mathrm{N}_{\mathrm{B}} \quad$ the buckling load

$l_{0}$ the effective length of the column 
Finally, the total design moment $\mathrm{M}_{\mathrm{Ed}}$, taking into account second-order effects, may be expressed as an increment of the bending moments resulting from a linear analysis (Eurocode, 2004):

$$
M_{E d}=M_{0 E d}\left[1+\frac{\beta}{\left(\frac{N_{B}}{N_{E d}}\right)-1}\right]
$$

with $\mathrm{M}_{0 \mathrm{Ed}} \quad$ the first-order moment

$\beta \quad$ a factor which depends on the distribution of 1 st and 2 nd order moments

$\mathrm{N}_{\mathrm{Ed}} \quad$ the design value of the axial load

$\mathrm{N}_{\mathrm{B}} \quad$ the buckling load based on the nominal stiffness

For isolated members with a constant cross section and an axial load, the second-order moment may be assumed to have a sine-shaped distribution. Then

$$
\beta=\frac{\pi^{2}}{c_{0}}
$$

with $\mathrm{c}_{0} \quad$ a coefficient which depends on the distribution of the first-order moments (for instance, $\mathrm{c}_{0}=8$ for a constant first-order moment).

Eq. (1) and Eq.(2), which are related to the bending stiffness and Eq.(3), which is determined by the first-order moment, could be directly adopted in case of fire.

\section{PARAMETRIC STUDY}

\subsection{Interaction diagrams at ambient temperature}

First, a simply supported column with a cross-section $300 \mathrm{~mm} \times 300 \mathrm{~mm}$, 4 bars with diameter 32 $\mathrm{mm}$ and concrete cover $25 \mathrm{~mm}$; concrete compressive strength $\mathrm{f}_{\mathrm{ck}}=55 \mathrm{MPa}$; reinforcement yield strength $\mathrm{f}_{\mathrm{yk}}=500 \mathrm{MPa}$ and Young's modulus of steel $\mathrm{E}_{\mathrm{s}}=2 \times 10^{5} \mathrm{~N} / \mathrm{mm}^{2}$ (the reinforcement ratio $\omega$ $\left.=(0.85 / 1.5) \mathrm{f}_{\mathrm{ck}} \mathrm{A}_{\mathrm{s}} /\left((1 / 1.15) \mathrm{f}_{\mathrm{yk}} \mathrm{A}_{\mathrm{c}}\right)=0.5\right)$ is investigated. In the following, the numerical method (whose results have been shown to be in good agreement with the experimental findings, see Wang et al., 2015), the stiffness method and the KLE method are adopted to obtain interaction curves of columns for different slenderness ratios, i.e. $\lambda=35,70$ and 105, at ambient temperature. The interaction diagrams are shown in Fig. 2, where $\mathrm{n}=\frac{\mathrm{N}_{\mathrm{c}}+\mathrm{N}_{\mathrm{g}}}{\mathrm{f}_{\mathrm{ck}} \mathrm{bh}}$ and $\mathrm{m}=\frac{\mathrm{M}_{\mathrm{c}}+\mathrm{M}_{\mathrm{g}}}{\mathrm{f}_{\mathrm{ck}} \mathrm{bh}^{2}}, \mathrm{~N}_{\mathrm{c}}, \mathrm{M}_{\mathrm{c}}, \mathrm{N}_{\mathrm{s}}, \mathrm{M}_{\mathrm{s}}$ are design values of normal forces and bending moments respectively for concrete and steel reinforcement, $\mathrm{b}$ is the width of the column and $\mathrm{h}$ is the height of the cross-section.

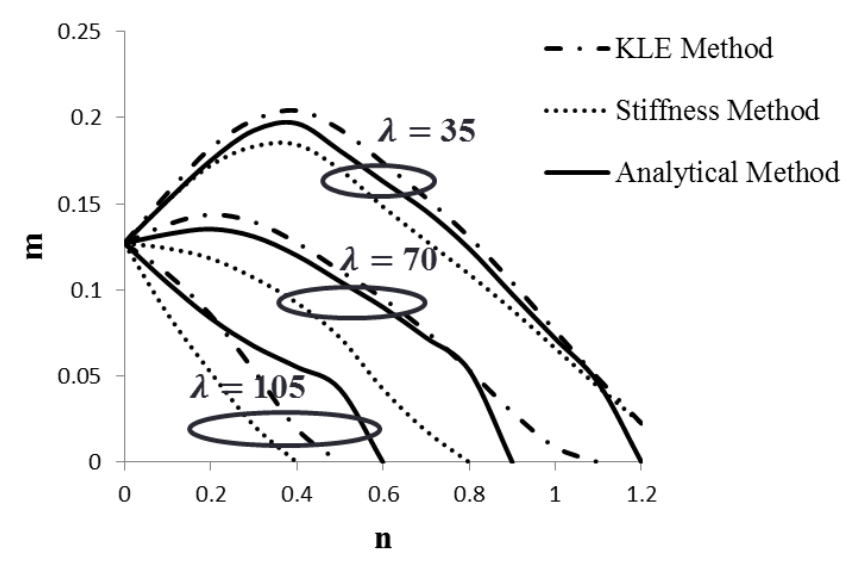

Fig. 2 Interaction diagrams of columns at ambient temperature for slenderness ratios 35, 70 and 105 adopting the KLE-method, the stiffness method and the numerical method

In Fig. 2, it is seen that at ambient temperature, the difference of the bending moment capacity obtained from these three approaches increases with the slenderness ratio. This difference between the KLE-method and the numerical method is no more than $7.0 \%$ in the range of all the permitted axial loads in case of slenderness ratios 35 and 70, while it reaches at maximum $26.2 \%(\mathrm{n}=0.3)$ in case of the slenderness ratio 105 . It is worth pointing out that with the numerical method, the 
bending moment capacity decreases significantly when the axial load is about to reach the load capacity. This is because the effect of imperfections is taken into account as an initial eccentricity, which leads to a significant bending moment in case of a large axial load. Comparatively, the KLEmethod has a good agreement with the numerical method. However, the prediction of the load capacity with the KLE-method is not always on the safe side in case of slenderness ratios 35 and 70, while the results with the stiffness method are too conservative for slender columns.

\subsection{Interaction diagrams at elevated temperatures}

Further, the same columns with slenderness ratios 35, 70 and 105 are used in case of a four-sided exposure to an ISO 834 fire. As the numerical tool has also been verified to be adopted in case of fire (Wang et al., 2015), the respective values of the bending moment capacity obtained with the KLE-method are compared with results from the numerical calculation in case of fire durations 30 minutes, 60 minutes and 90 minutes (Table 1).

Table 1. Comparison of respective values of the bending moment capacity in case of an ISO 834 fire

\begin{tabular}{|c|c|c|c|c|c|c|}
\hline \multirow{2}{*}{$\begin{array}{c}\text { Fire } \\
\text { duration } \\
(\min )\end{array}$} & \multirow{2}{*}{$\begin{array}{c}\text { Slenderness } \\
\text { ratio } \lambda[-]\end{array}$} & \multirow[b]{2}{*}{ Axial load n [-] } & \multicolumn{2}{|c|}{ Bending moment $\mathrm{m}[-]$} & \multirow{2}{*}{$\frac{(2)-(1)}{(2)} \%$} & \multirow[b]{2}{*}{ Evaluation } \\
\hline & & & $\begin{array}{l}\text { KLE- } \\
\text { method (1) }\end{array}$ & $\begin{array}{l}\text { Numerical } \\
\text { method (2) }\end{array}$ & & \\
\hline \multirow{9}{*}{30} & \multirow{5}{*}{35} & 0.1 & 0.14 & 0.13 & -7.7 & unsafe \\
\hline & & 0.3 & 0.15 & 0.14 & -7.1 & unsafe \\
\hline & & 0.5 & 0.11 & 0.10 & -10.0 & unsafe \\
\hline & & 0.7 & 0.05 & 0.05 & 0.0 & safe \\
\hline & & 0.9 & 0.01 & 0.00 & - & unsafe \\
\hline & \multirow{3}{*}{70} & 0.1 & 0.11 & 0.09 & -22.2 & unsafe \\
\hline & & 0.2 & 0.08 & 0.07 & -14.3 & unsafe \\
\hline & & 0.3 & 0.04 & 0.05 & 20.0 & safe \\
\hline & 105 & 0.1 & 0.05 & 0.06 & 16.7 & safe \\
\hline \multirow{4}{*}{60} & \multirow{3}{*}{35} & 0.1 & 0.11 & 0.10 & -10.0 & unsafe \\
\hline & & 0.3 & 0.09 & 0.08 & -12.5 & unsafe \\
\hline & & 0.5 & 0.03 & 0.03 & 0.0 & safe \\
\hline & 70 & 0.1 & 0.05 & 0.05 & 0.0 & safe \\
\hline \multirow{2}{*}{90} & \multirow{2}{*}{35} & 0.1 & 0.06 & 0.05 & -20.00 & unsafe \\
\hline & & 0.3 & 0.02 & 0.02 & 0.00 & safe \\
\hline
\end{tabular}

Table 1 shows that it is unsafe to implement the traditional KLE-method for predicting the stiffness as well as the bending moment capacity of columns in case of fire. This risk of buckling is rather high in the two extreme situations of "small axial loads" and of "large axial loads, close to the axial capacity". Among the effect of all the parameters, we can see that the differences on the bending moment capacity between the numerical method and the KLE-method increase significantly in function of the fire duration. This is probably because the slope which represent the stiffness after the point of $0.8 \mathrm{M}_{\mathrm{Ed}}$ changes significantly and this value of the slope is not representative for the stiffness in case of fire. Hence, it is significant to investigate the changes of the stiffness of the column in function of fire and find a safer coefficient to evaluate the bending moment of columns in case of fire.

Hence, the cross-sectional numerical calculation tool is adopted to find a point of the momentcurvature curve which can represent the stiffness of columns to extend the applicability of the KLEmethod to the case of an ISO 834 fire. The aforementioned columns of slenderness ratios 35, 70 and 105 are studied in case of fire durations 0 minutes, 30 minutes, 60 minutes and 90 minutes. The ratio of the bending moment corresponding to the respective value of the stiffness to the bending moment capacity of columns in case of different axial loads as well as different fire durations in case of slenderness ratios 35, 70 and 105 are listed in Table 2. 
Table 2. Comparison of the ratio of the bending moment corresponding to the respective value of the stiffness to the bending moment capacity in case of an ISO 834 fire

\begin{tabular}{|c|c|c|c|c|c|c|c|c|c|c|}
\hline $\begin{array}{c}\text { Column } \\
\begin{array}{c}\text { Fire duration } \\
\text { (min) }\end{array}\end{array}$ & \multicolumn{4}{|c|}{$\begin{array}{c}\text { Slenderness ratio } \\
\lambda=35\end{array}$} & \multicolumn{3}{c|}{$\begin{array}{c}\text { Slenderness ratio } \\
\lambda=70\end{array}$} & \multicolumn{3}{c|}{$\begin{array}{c}\text { Slenderness ratio } \\
\lambda=105\end{array}$} \\
\hline $\begin{array}{c}\text { Axial load n } \\
{[-]}\end{array}$ & $\begin{array}{c}0 \\
\text { min }\end{array}$ & $\begin{array}{c}30 \\
\text { min }\end{array}$ & $\begin{array}{c}60 \\
\text { min }\end{array}$ & $\begin{array}{c}90 \\
\text { min }\end{array}$ & $\begin{array}{c}0 \\
\text { min }\end{array}$ & $\begin{array}{c}30 \\
\text { min }\end{array}$ & $\begin{array}{c}60 \\
\text { min }\end{array}$ & $\begin{array}{c}0 \\
\text { min }\end{array}$ & $\begin{array}{c}30 \\
\text { min }\end{array}$ & $\begin{array}{c}60 \\
\text { min }\end{array}$ \\
\hline 0.1 & 0.99 & 0.97 & 0.96 & 0.93 & 0.97 & 0.93 & 0.79 & 0.96 & 0.78 & 0.32 \\
\hline 0.2 & 0.98 & 0.94 & 0.93 & 0.65 & 0.96 & 0.93 & 0.63 & 0.84 & 0.30 & - \\
\hline 0.3 & 0.98 & 0.95 & 0.93 & - & 0.94 & 0.52 & - & 0.68 & - & - \\
\hline 0.4 & 0.99 & 0.97 & 0.52 & - & 0.87 & 0.61 & - & 0.60 & - & - \\
\hline 0.5 & 0.98 & 0.93 & 0.61 & - & 0.85 & 0.57 & - & 0.55 & - & - \\
\hline 0.6 & 0.98 & 0.93 & 0.57 & - & 0.85 & - & - & - & - & - \\
\hline 0.7 & 0.98 & 0.91 & - & - & 0.86 & - & - & - & - & - \\
\hline 0.8 & 0.99 & 0.88 & - & - & 0.80 & - & - & - & - & - \\
\hline 0.9 & 0.99 & - & - & - & - & - & - & - & - & - \\
\hline 1 & 0.98 & - & - & - & - & - & - & - & - & - \\
\hline 1.1 & 0.97 & - & - & - & - & - & - & - & - & - \\
\hline
\end{tabular}

From Table. 2, it is observed that the ratio of the assumed average bending moment to the bending moment capacity decreases in function of the fire duration as well as the function of the slenderness ratio. An interpolation value can be used for columns with intermediate slenderness ratios in case of an ISO 834 fire of intermediate fire durations. It is worth pointing out that a higher ratio than 0.8 is suggested as a simplification for the stiffness of the column adopted in the KLE-method. Although $0.8 \mathrm{M}_{\mathrm{Ed}}$ is indicated to be less conservative for the KLE-method, the difference on the bending moment (shown in Table 1) between the KLE-method and the numerical method is maximum 10.0 $\%$ in case of the slenderness ratio 35 and the fire duration 30 minutes, while it is $7.0 \%$ at ambient temperature. It means that the slope of the moment-curvature curve between $0.8 \mathrm{M}_{\mathrm{Ed}}$ and $\mathrm{M}_{\mathrm{Ed}}$ varies very slightly in case the column is not too slender and the fire exposure does not exceed 30 minutes. However, the slope at $0.8 \mathrm{M}_{\mathrm{Ed}}$ cannot always be used as the stiffness of the column considering the evaluation according to Table 1 . Hence, it is suggested to replace 0.8 by the coefficient which is larger than 0.8 presented in Table 2 .

\subsection{Validation}

In order to verify the versatility of coefficients shown in Table 2, a column with a different crosssection $400 \mathrm{~mm} \times 400 \mathrm{~mm}$, but the same reinforcement ratio 0.5 and the slenderness ratio 35 is chosen. The differences on the interaction relationship of columns exposed to an ISO fire 834 with fire durations 0 minutes, 30 minutes, 60 minutes and 90 minutes are illustrated in Table 3 adopting the proposed coefficients for the KLE-method in case of the slenderness ratio 35 and are compared with the results from the numerical method. 
Table 3. Comparison of respective values of the bending moment capacity in case of an ISO 834 fire

\begin{tabular}{|c|c|c|c|}
\hline \multirow[b]{2}{*}{$\begin{array}{l}\text { Fire duration } \\
\quad \text { (min) }\end{array}$} & \multirow[b]{2}{*}{ Axial load n [-] } & \multicolumn{2}{|c|}{ Bending moment $\mathrm{m}[-]$} \\
\hline & & $\begin{array}{c}\text { KLE- } \\
\text { method (1) }\end{array}$ & $\begin{array}{l}\text { Numerical } \\
\text { method (2) }\end{array}$ \\
\hline \multirow{6}{*}{0} & 0.1 & 0.15 & 0.16 \\
\hline & 0.3 & 0.20 & 0.20 \\
\hline & 0.5 & 0.19 & 0.19 \\
\hline & 0.7 & 0.15 & 0.15 \\
\hline & 0.9 & 0.10 & 0.10 \\
\hline & 1.1 & 0.05 & 0.05 \\
\hline \multirow{4}{*}{30} & 0.1 & 0.15 & 0.15 \\
\hline & 0.3 & 0.17 & 0.17 \\
\hline & 0.5 & 0.14 & 0.14 \\
\hline & 0.7 & 0.09 & 0.09 \\
\hline \multirow{2}{*}{60} & 0.1 & 0.13 & 0.13 \\
\hline & 0.3 & 0.13 & 0.13 \\
\hline 90 & 0.1 & 0.10 & 0.10 \\
\hline
\end{tabular}

In Table 3, it is seen that the difference is very small after the correction is used for calculating the stiffness of columns with the KLE-method.

\section{CONCLUSIONS}

Comparing the KLE-method with the stiffness method and the numerical method at ambient temperature as well as with numerical method at elevated temperatures, the following conclusions are obtained:

1) The bending moment capacity predicted with the KLE method agrees fairly well with the results yielded by the numerical method. However, the capacity calculated with the KLE-method is slightly on the unsafe side, while the results with the stiffness method is too conservative.

2) The stiffness of the column obtained with the slope of the moment-curvature curve assumed at $0.8 \mathrm{M}_{\mathrm{Ed}}$ in the Dutch prescriptions (NEN, 1995) is not available in case of fire. A value corresponding to a higher bending moment is recommended for the assumption of the stiffness in case of fire.

3) The ratio of the assumed bending moment to the bending moment capacity is given for slenderness ratios 35, 70, 105 in case of fire durations 0 minutes, 30 minutes, 60 minutes and 90 minutes. An interpolated value could be adopted in the range of the slenderness ratio from 0 to 105 and the fire duration from 0 to 90 minutes of an ISO 834 fire exposure. The proposed values have been validated for another case and yield robust results.

\section{ACKNOWLEDGMENTS}

The authors would like to thank the China Scholarship Council (CSC) for the financial support.

\section{REFERENCES}

CEN. "EN 1992-1-1: Design of concrete structures - Part 1-1: General rules and rules for buildings.", European Committee for Standardization, Brussels, Belgium, 2004.

CEN. "EN 1992-1-2: Design of concrete structures - Part 1-2: General rules - Structural fire design.", European Committee for Standardization, Brussels, Belgium, 2004.

NEN, "NEN 6720 Technische Grondslagen voor Bouwvoorschriften, Voorschriften Beton TGB 1990 Constructieve Eisen en Rekenmethoden (VBC 1995)," Civieltechnisch centrum uitvoering research en regelgeving, Nederlands Normalisatie-instituut, ; Delft, The Netherlands, 1995.

Wang L. J., Caspeele R., Van Coile R. \& Taerwe L. "Extension of tabulated design parameters for rectangular columns exposed to fire taking into account second-order effects and various fire models". Structural Concrete, 16(1), 17-35, 2015. 